\title{
Danos causados por doenças fúngicas no arroz cultivado em várzeas no Sul do Estado do Tocantins
}

\author{
Gil Rodrigues dos Santos $\left(\left(^{1 *}\right)\right.$; Jaíza Francisca Ribeiro Chagas $\left({ }^{2}\right)$; Aline Torquato Tavares $\left({ }^{2}\right)$; \\ Manoel Delintro de Castro Neto ('); Renato de Almeida Sarmento ('); Aloísio Freitas Chagas \\ Júnior ('); Ildon Rodrigues do Nascimento (')
}

(') Universidade Federal do Tocantins (UFT), Campus de Gurupi, Zona Rural, 77402-970 Gurupi (TO), Brasil.

(2) UFT, Programa de Pós-Graduação em Produção Vegetal, 77402-970 Gurupi (TO), Brasil.

(*) Autor correspondente: gilrsan@uft.edu.br

Recebido: 12/abr./2011; Aceito: 1.\%/jul./2011

\begin{abstract}
Resumo
Neste estudo, foram avaliados os danos causados por doenças fúngicas no arroz cultivado sob condição de várzea no Estado do Tocantins. O delineamento experimental foi o de blocos casualizados com quatro repetições em esquema fatorial 26 (genótipos de arroz irrigado) × 2 (aplicação ou não de fungicidas). As aplicações de fungicidas foram realizadas aos 35 dias após a semeadura (tiofanato metílico; $0,5 \mathrm{~L} \mathrm{ha}^{-1}$ ) nos estádios de emborrachamento (trifloxistrobina + propiconazole; $0,6 \mathrm{~L}$ $\mathrm{ha}^{-1}$ ) e com 5\% das panículas emitidas (trifloxistrobina + propiconazole; 0,6 L ha-1 + tebuconazole; 0,75 L ha-1). As variáveis avaliadas foram: severidades da brusone nas folhas e nas panículas, mancha-parda nas folhas, mancha dos grãos, massa de cem sementes e produtividade. O tratamento com fungicida reduziu, em média, a severidade da brusone nas folhas em $69 \%$ e em 54\% a brusone nas panículas. Não houve diferença estatística entre os tratamentos com e sem fungicida na severidade da mancha parda; porém alguns genótipos diferiram estatisticamente entre eles. Nas plantas tratadas com fungicidas, houve um acréscimo médio de 0,52 g (17,6\%) na massa de cem sementes e de $1000 \mathrm{~kg} \mathrm{ha}^{-1}$ na produtividade (12,6\%). Os valores máximos obtidos na massa de cem sementes e na produtividade foram, respectivamente, de $3,2 \mathrm{~g}$ e $9270 \mathrm{~kg} \mathrm{ha}^{-1}$.
\end{abstract}

Palavras-chave: brusone, doenças foliares, mancha dos grãos, mancha-parda, Oryza sativa.

\section{Damage caused by fungal diseases in rice grown in lowland at the southern of the State of Tocantins, Brazil}

\section{Abstract}

This study aimed to evaluate the damages caused by the fungal diseases in rice production under conditions of lowland at the State of Tocantins. The experimental design was a randomized blocks with four replications, in a factorial scheme of 26 (genotypes of irrigated rice) $\times 2$ (plots treated or untreated with fungicides). The fungicide treatment consisted of three applications, the first one was done 35 days after planting with thiophanate methyl $(0.5 \mathrm{~L} \mathrm{ha-1})$, the second application was done in the booting stage of rice with trifloxystrobin + propiconazole $\left(0.6 \mathrm{~L} \mathrm{ha}^{-1}\right)$ and the third application was done with $5 \%$ of panicles issued with trifloxystrobin + propiconazole $\left(0.6 \mathrm{~L} \mathrm{ha}^{-1}\right)+$ tebuconazole $\left(0.75 \mathrm{~L} \mathrm{ha}^{-1}\right)$. The following evaluations were performed: leaf and panicle blast severity, brown-spot severity, grains spots, 100 seed mass, and productivity. The fungicide treatments decreased around 69\% the blast severity on leaves and 54\% on panicles of most genotypes. There was not any statistical difference in the treatment with or without fungicide for brown-spot, however there was statistical difference among the genotypes. In plants treated with fungicides there was an increase of $0.52 \mathrm{~g}(17.6 \%)$ in the mass of 100 seeds and $1000 \mathrm{~kg} \mathrm{ha}^{-1}$ in the productivity (12.6\%). The maximum values obtained in 100 seeds mass and yield were $3.19 \mathrm{~g}$ and $9270 \mathrm{~kg} \mathrm{ha}^{-1}$, respectively.

Key words: blast, foliar diseases, grain discoloration, brown spot, Oryza sativa. 


\section{INTRODUÇÃO}

As doenças causadas por fungos são os principais problemas da orizicultura mundial (PrabHu et al., 2006). Atualmente, a área plantada com arroz irrigado no Estado do Tocantins é de aproximadamente 53.890 hectares (Secretaria..., 2009), com produtividade média de 4.371 $\mathrm{kg} \mathrm{ha}^{-1}$. O arroz, em todas as fases de desenvolvimento, é afetado por diversas doenças que reduzem a produtividade e afetam a qualidade dos grãos (PrabHu et al., 2006), bem como a qualidade sanitária e fisiológica das sementes.

Entre as inúmeras doenças que acometem a cultura do arroz irrigado, a brusone é a mais destrutiva e de ocorrência em todo o território brasileiro. Nas lavouras com cultivares suscetíveis e condições favoráveis, as perdas podem chegar a 100\% (SAnTos et al., 2002). A doença ocorre na fase vegetativa até aos 50 dias após a emergência e na fase reprodutiva da planta no período de formação e maturação dos grãos (PhabHu et al., 2006). Porém, quando as condiçóes ambientais tornam-se favoráveis, as plantas podem ser infectadas em qualquer estádio fenológico. Nas folhas, a doença se manifesta como manchas necróticas elípticas enquanto no colmo como necrose no pescoço da panícula (Prabhu et al., 1995). Na cultura do arroz, ao longo de vários anos, os programas de melhoramento do país têm desenvolvido diversas cultivares com resistência vertical à brusone (SANTOS et al., 2002), porém geneticamente semelhantes. No Estado do Tocantins, dentro do manejo integrado de doenças do arroz a principal medida de controle atualmente é o uso de cultivares resistentes associados ao uso de fungicidas. Devido à alta variabilidade na população de Pyricularia grisea associada a semeaduras de uma única cultivar em áreas acima de 10.000 ha e condiçôes ambientais favoráveis à brusone, cultivares com genes de resistência vertical semelhantes deixam de ser efetivas com apenas dois a três anos de cultivo, pois novas raças do patógeno são capazes de suplantar essa resistência (SAntos et al., 2005; Dias Neto et al., 2010). A falta de opção em termos de cultivares adaptadas e geneticamente distintas constitui-se no principal problema que limita o cultivo do arroz irrigado no Estado do Tocantins (SANTos et al., 2002).

A mancha parda, causada pelo fungo Bipolaris oryzae (Breda de Hann) Shoemaker, tem sido considerada a segunda doença mais importante para a cultura do arroz na maioria dos países. Esta doença ocorre na fase vegetativa e reprodutiva da planta e pode causar danos de $12 \%$ a $30 \%$ na massa dos grãos e de $18 \%$ a $22 \%$ no número de grãos cheios por panícula. Os sintomas nas folhas ocorrem como manchas ovais de cor marrom com centro acinzentado (Prabhu et al., 1995), além de provocar grãos com chochamento e perda de qualidade por causa do gessamento e coloração escura (Prabhu e Filippi, 1997).

Segundo Prabhu et al., (2006), a mancha dos grãos aparece desde a fase de emissão das panículas até o amadurecimento dos grãos e é causada por um complexo de fungos sendo principalmente Bipolaris sp., Microdochium oryzae, Alternaria padwickii, Sarocladium oryzae, Nigrospora sp., Pyricularia grisea e Phoma sp. Esta doença ocorre na fase de formação de grãos e tem sido uma preocupação devido aos prejuízos causados nas lavouras de vários Estados brasileiros tais como Goiás (Costa, 1991); Mato Grosso (Souza, 1993) e Tocantins (SAntos et al., 1994).

Outra preocupação constante é a ineficiência de fungicidas pulverizados na parte aérea que contribui para aumentar o custo de produção (Prabhu et al., 1995; Santos et al., 2002). Atualmente na regiáo do Vale do Araguaia, os produtores precisam fazer até quatro aplicaçóes de fungicidas para conseguirem produzir satisfatoriamente.

Diante dessa situaçáo e considerando a importância do arroz irrigado para o Estado do Tocantins, o desenvolvimento de programas de manejo adequados às condiçóes agroecológicas das várzeas torna-se uma prioridade das instituições de pesquisa. Os atuais danos causados por doenças fúngicas no Sul do Estado do Tocantins são desconhecidos, sendo de fundamental importância para a definição de qualquer estratégia de controle. Assim, o objetivo deste estudo foi quantificar os danos em produtividade causados por doenças fúngicas em arroz cultivado em várzeas no Sul do Tocantins, bem como a viabilidade de se utilizar fungicidas para o controle dessas doenças.

\section{MATERIAL E MÉTODOS}

O experimento foi realizado na safra de 2008/2009, em condiçôes de várzeas, no Município de Formoso do Araguaia, Tocantins, com as seguintes coordenadas geo-

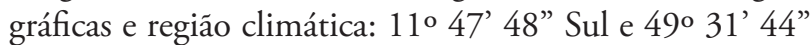
Oeste, altitude de $240 \mathrm{~m}$, clima tropical de veráo úmido de acordo com a classificação de Köppen. Foram utilizados genótipos cujas sementes foram cedidas pela Embrapa Arroz e Feijão. O delineamento experimental foi o de blocos casualizados, com quatro repetiçốes, em esquema fatorial $26 \times 2$. Os fatores foram genótipos de arroz irrigado (Tabela 2) e a aplicação ou não de fungicidas. O genótipo resistente (controle local) foi o Jaçaná lançado em 2007 e atualmente ocupa mais de 30\% da área plantada no Tocantins. O genótipo Metica-1 foi considerado como testemunha suscetível já que vem sendo usado há mais de 12 anos na regiáo. A densidade de semeadura foi de cem sementes por metro linear. O experimento foi constituído de 208 parcelas, sendo cada uma delas representada por quatro linhas de 5 metros de comprimento e com espaçamento de 0,20 $\mathrm{m}$ entre linhas. A área útil da parcela foi de $1,6 \mathrm{~m}^{2}$ constituída pelas duas linhas centrais, desprezando-se também $0,5 \mathrm{~m}$ do comprimento de cada extremidade da linha. A análise química de amostras de solo da camada de $0-20 \mathrm{~cm}$ de profundidade demonstrou 
os seguintes resultados: matéria orgânica $=23 \mathrm{~g} \mathrm{dm}^{-3}$; $\mathrm{pHCaCl}_{2}=5,2 ; \mathrm{P}=28,8 \mathrm{mg} \mathrm{dm}^{-3} ; \mathrm{K}=0,26 \mathrm{cmol}_{\mathrm{c}} \mathrm{dm}^{-3}$; $\mathrm{Ca}+\mathrm{Mg}=2,92 \mathrm{cmol} \mathrm{dm}_{\mathrm{c}}^{-3} ; \mathrm{H}+\mathrm{Al}=6,6 \mathrm{cmol}_{\mathrm{c}} \mathrm{dm}^{-3} \mathrm{e}$ saturação de bases $=32,5 \%$ de acordo com metodologia proposta pela EMBRAPA (1997). A adubação de semeadura recomendada a partir da análise de solo $\left(400 \mathrm{~kg} \mathrm{ha}^{-1} \mathrm{da}\right.$ fórmula NPK 05-25-15) foi realizada a lanço. A uréia foi aplicada em cobertura aos 19 e 33 dias após a semeadura na dosagem de $75 \mathrm{~kg} \mathrm{~N} \mathrm{ha}^{-1}$ em cada aplicaçấo. A partir dos 25 dias da emergência das plântulas, o arroz foi submetido à imersão em altura constante de $15 \mathrm{~cm}$ de lâmina de água até o fim do ciclo.

As pulverizaçôes dos fungicidas nas parcelas foram feitas em três períodos, sendo cada um deles realizado no mesmo dia devido à semelhança no ciclo vegetativo dos genótipos. Os fungicidas registrados para cultura do arroz foram utilizados de acordo com o manejo adotado pelos produtores da regiáo visando ao controle da maioria das doenças do arroz. A primeira aplicação foi feita aos 35 dias após a semeadura com o fungicida tiofanato metílico $\left(0,5 \mathrm{~L} \mathrm{ha}^{-1}\right)$ para o controle da brusone das folhas. A segunda pulverização foi no estádio de emborrachamento com os fungicidas trifloxistrobina + propiconazole $\left(0,6 \mathrm{~L} \mathrm{ha}^{-1}\right)$ visando ao controle da brusone das panículas e da mancha parda. A terceira aplicação foi feita quando as plantas estavam com $5 \%$ das panículas emitidas com trifloxistrobina + propiconazole $\left(0,6 \mathrm{~L} \mathrm{ha}^{-1}\right)$ e tebuconazole $\left(0,75 \mathrm{~L} \mathrm{ha}^{-1}\right)$ visando ao controle da brusone das panículas e da mancha dos grãos. As aplicaçôes dos fungicidas foram feitas pela manhã, em dias ensolarados, com umidade relativa em torno de $75 \%$ e temperatura variando de 29 a $33{ }^{\circ} \mathrm{C}$. Utilizou-se um pulverizador costal pressurizado a $\mathrm{CO}_{2}$, bico cônico, com pressão ajustada para $4,84 \mathrm{lb} \mathrm{pol}^{-2}$ e volume de calda regulado para $200 \mathrm{~L}$ ha.

As quantificaçóes da severidade da brusone nas folhas e da mancha parda foram realizadas nas plantas da área útil das parcelas com ou sem aplicação de fungicidas. Foi utilizada uma escala de notas proposta pelo International Rice Research Institute (IRRI, 1996) levando-se em consideração a severidade das doenças nas folhas. As notas foram atribuídas conforme análise visual do tecido foliar afetado sendo: nota 0 - ausência de lesôes; nota 1 - abaixo de $1 \%$ de tecido doente (área foliar/grãos); nota 3 - de $1 \%$ a $5 \%$ da área foliar/tecido doente; nota 5 - de $6 \%$ a $25 \%$ da área foliar/tecido doente; nota 7 - de $26 \%$ a $50 \%$ da área foliar/tecido doente e nota 9 - acima de $50 \%$ da área foliar/tecido doente. $\mathrm{Na}$ avaliação da mancha dos grãos, adotou-se a mesma escala de notas (IRRI, 1996) considerando-se a porcentagem de grãos infectados. Para a brusone nas panículas, utilizou-se a escala recomendada pelo International Rice Research Institute (IRRI, 1996) em que: nota 0 - sem incidência; nota 1 - menos que $5 \%$ de panículas infectadas; nota 3 - de $5 \%$ a $10 \%$ de panículas infectadas; nota 5 - entre $11 \%$ e $25 \%$ de panículas infectadas; nota 7 - entre $26 \%$ e $50 \%$ de panículas infectadas e nota
9 - maior do que 50\% de panículas infectadas. Para todas as doenças, foi considerado resistente o genótipo com nota de severidade menor ou igual a 3 e suscetível, com notas superiores a 3. Foram quantificadas as severidades da brusone nas folhas e nas panículas, mancha parda nas folhas e mancha dos grãos. As avaliaçóes das doenças foram realizadas levando-se em consideraçáo o período de maior suscetibilidade da planta. As avaliações da brusone nas folhas foram feitas aos 45 dias após a semeadura, da mancha parda na fase de florescimento e da brusone nas panículas e mancha dos grãos na fase de grão pastoso.

Foi determinada a produtividade de cada genótipo em todas as parcelas pela coleta e pesagem das sementes. A estimativa dos danos foi realizada de acordo com BRITo et al. (2007). A diferença de produtividade $\left(\mathrm{kg} \mathrm{ha}^{-1}\right)$ corrigida para $13 \%$ de umidade foi expressa em porcentagem entre parcelas que receberam ou náo aplicaçáo de fungicidas pela expressão:

Porcentagem de dano $(\text { parcela })_{\mathrm{ij}}=$ PMECC $_{\mathrm{i}}-\mathrm{PPESC}_{\mathrm{i}} /$ $\left[\right.$ PMECC $\left._{\mathrm{i}}\right] \times 100$

Em que:

Porcentagem de dano (parcela) ${ }_{\mathrm{ij}}$ - porcentagem de dano referente à parcela que recebeu a cultivar ${ }_{i}$ na repetiçáo ${ }_{j}$ PMECC $_{i}$ - produção média da cultivar ${ }_{i}$ obtida nos tratamentos com controle químico da doença

PPESC $_{i}$ - produção por parcela da cultivar ${ }_{i}$ nos tratamentos sem controle químico da doença

Os dados da severidade da brusone nas folhas e nas panículas, mancha parda nas folhas e mancha de gráos foram transformados para $\sqrt{\chi+0,5}$ visando obter homogeneidade de variância (SiLva e SiLva, 1999) e submetidos à análise de variância e comparação de médias pelo teste de agrupamento Scott-Knott a 5\% de probabilidade.

\section{RESULTADOS E DISCUSSÃO}

De acordo com os resultados obtidos na análise de variância (Tabela 1), foi constatada diferença significativa $(\mathrm{p}<0,01)$, pelo teste $\mathrm{F}$, para as variáveis severidade de brusone nas folhas, mancha parda, brusone nas panículas, mancha dos grãos, massa de cem sementes e produtividade, estudadas dentro dos fatores genótipos $(\mathrm{G})$ e aplicação ou não de fungicidas (F). Verificou-se interação significativa $\mathrm{G} \times \mathrm{F}$ para as variáveis severidades da brusone nas folhas, brusone das panículas, massa de cem sementes e produtividade.

Todos os genótipos testados foram suscetíveis à brusone nas folhas, com nota de severidade acima de 3 nas parcelas sem aplicação de fungicida (Tabela 2). A aplicação de fungicidas foi eficiente no controle da brusone nas folhas para todos os genótipos testados com exceção da 
Tabela 1. Análise de variância dos valores de severidade da brusone foliar (BF), mancha parda (MP), mancha dos grãos (MG), brusone nas panículas (BP), massa de cem sementes e produtividade de genótipos de arroz irrigado na safra 2008/2009, em Formoso do Araguaia, Tocantins

\begin{tabular}{lccccccc} 
Fontes de variação & $* *$ & BF & MP & MG & BP & Massa de cem sementes (g) & Produtividade (kg ha-1) \\
Repetição & 3 & 0,040 & 0,100 & 0,373 & 5,153 & 0,111 & 4545817,307 \\
Fungicidas (F) & 1 & $35,063^{*}$ & 0,001 & $22,882^{*}$ & $315,076^{*}$ & $14,485^{*}$ & $51900048,076^{*}$ \\
Genótipos (G) & 25 & $0,112^{*}$ & $0,277^{*}$ & $0,405^{*}$ & $5,830^{*}$ & $0,124^{*}$ & $4109417,307^{*}$ \\
\hline F G & 25 & $0,102^{*}$ & 1,776 & 0,191 & $2,836^{*}$ & $0,142^{*}$ & $2787248,076^{*}$ \\
Resíduo & 153 & 0,042 & 0,028 & 0,0616 & 0,983 & 0,079 & 1888562,405 \\
CV (\%) & & 12,17 & 7,78 & 13,09 & 29,82 & 10,47 & 18,56
\end{tabular}

*Significativo a $1 \%$ de probabilidade pelo teste $\mathrm{F} ;{ }^{* *} \mathrm{GL}=$ graus de liberdade.

cultivar Andosan que não diferiu nos tratamentos com ou sem aplicação de fungicidas. Para a brusone nas panículas (Tabela 2), a aplicação de fungicidas reduziu significativamente a nota de severidade para a maioria dos genótipos testados. Não houve diferença estatística entre os tratamentos com ou sem aplicaçáo de fungicidas para os genótipos AB061008, AB061196 e CNA11014. Segundo BASTIAANS et al. (1994), as perdas causadas pela brusone nas folhas são indiretas, pois as lesôes diminuem a área foliar e afetam a fotossíntese.

Outros autores também verificaram eficiência no controle da brusone com fungicidas. Oliveira et al. (2001), estudando os efeitos de produtos fitossanitários, em condiçôes de campo, visando ao controle da brusone observaram que os tratamentos com fungicidas demonstraram eficiência em reduzir a incidência da brusone nas folhas em relação à testemunha. SiLva et al. (2003) também encontraram resultados semelhantes com relação à brusone nas panículas com redução da severidade com o uso de fungicidas em sistema de plantio direto e convencional.

Nas plantas que não receberam aplicação de fungicidas, os genótipos AB061050, BRA051021 e BRA051135 tiveram os menores valores de severidade para a brusone nas panículas (nota 3), porém foram suscetíveis à brusone nas folhas nas mesmas condiçôes (Tabela 2). A brusone nas panículas é considerada a doença que ocorre na fase mais importante da cultura, pois está mais relacionada com as perdas em rendimento e pode ocorrer com alta severidade, mesmo não sendo precedida por maior severidade da brusone nas folhas (Bonman et al., 1992).

A maioria dos genótipos testados foi suscetível à mancha parda e à mancha dos grãos (Tabela 3) com ou sem a aplicação de fungicidas. Os genótipos AB061050, BRA051129 e BRA051130 foram considerados os mais resistentes à mancha parda, e Jaçaná, Andosan, AB061008, AB061179, AB061196, BRA051250, CNA10892, CNA11014 e SCS112 os mais suscetíveis. Não houve diferença significativa na resistência dos genótipos à mancha dos grãos com ou sem aplicaçáo de fungicidas. Estes resultados demonstraram que os fungicidas trifloxistrobina + propiconazole e tebuconazole aplicados nas fases de emborrachamento e ou em plantas com $5 \%$ das panículas emitidas não foram eficazes, nas
Tabela 2. Valores médios da severidade da brusone nas folhas e nas panículas em genótipos de arroz irrigado com (CF) ou sem (SF) aplicação de fungicidas na safra 2008/2009 em Formoso do Araguaia, Tocantins

\begin{tabular}{|c|c|c|c|c|}
\hline \multirow{3}{*}{ Genótipos } & \multicolumn{4}{|c|}{ Doenças } \\
\hline & \multicolumn{2}{|c|}{ Brusone nas folhas } & \multicolumn{2}{|c|}{ Brusone nas panículas } \\
\hline & CF & SF & CF & SF \\
\hline AB061008 & $2,50 \mathrm{bA}$ & $4,50 \mathrm{aB}$ & $4,00 \mathrm{cA}$ & $4,50 \mathrm{aA}$ \\
\hline AB061021 & $1,00 \mathrm{aA}$ & $5,00 \mathrm{aB}$ & $2,00 \mathrm{bA}$ & $3,50 \mathrm{aB}$ \\
\hline AB061050 & $1,00 \mathrm{aA}$ & $4,00 \mathrm{aB}$ & $1,00 \mathrm{aA}$ & $3,00 \mathrm{aB}$ \\
\hline AB061055 & $1,00 \mathrm{aA}$ & $4,00 \mathrm{aB}$ & $1,00 \mathrm{aA}$ & $4,00 \mathrm{aB}$ \\
\hline AB061179 & $1,00 \mathrm{aA}$ & $3,50 \mathrm{aB}$ & $2,50 \mathrm{bA}$ & $4,00 \mathrm{aB}$ \\
\hline AB061196 & $1,00 \mathrm{aA}$ & $4,00 \mathrm{aB}$ & $4,50 \mathrm{cA}$ & $5,50 \mathrm{bA}$ \\
\hline BRA051021 & $1,50 \mathrm{aA}$ & $4,50 \mathrm{aB}$ & $1,00 \mathrm{aA}$ & $3,00 \mathrm{aB}$ \\
\hline BRA051077 & $1,00 \mathrm{aA}$ & $4,00 \mathrm{aB}$ & $2,50 \mathrm{bA}$ & $4,50 \mathrm{bB}$ \\
\hline BRA051083 & $1,00 \mathrm{aA}$ & $3,50 \mathrm{aB}$ & $2,00 \mathrm{bA}$ & $4,00 \mathrm{aB}$ \\
\hline BRA051108 & $1,00 \mathrm{aA}$ & $4,50 \mathrm{aB}$ & $1,50 \mathrm{aA}$ & $5,00 \mathrm{bB}$ \\
\hline BRA051126 & $1,00 \mathrm{aA}$ & $3,50 \mathrm{aB}$ & $1,00 \mathrm{aA}$ & $6,00 \mathrm{bB}$ \\
\hline BRA051129 & $1,00 \mathrm{aA}$ & $4,50 \mathrm{aB}$ & $1,00 \mathrm{aA}$ & $3,50 \mathrm{aB}$ \\
\hline BRA051130 & $1,00 \mathrm{aA}$ & $4,50 \mathrm{aB}$ & $1,00 \mathrm{aA}$ & $4,50 \mathrm{bB}$ \\
\hline BRA051134 & $1,00 \mathrm{aA}$ & $4,00 \mathrm{aB}$ & $1,00 \mathrm{aA}$ & $3,50 \mathrm{aB}$ \\
\hline BRA051135 & $1,00 \mathrm{aA}$ & $3,50 \mathrm{aB}$ & $1,00 \mathrm{aA}$ & $3,00 \mathrm{aB}$ \\
\hline BRA051250 & $1,00 \mathrm{aA}$ & $4,50 \mathrm{aB}$ & $3,00 \mathrm{bA}$ & $4,50 \mathrm{bB}$ \\
\hline CNA10892 & $1,00 \mathrm{aA}$ & $4,00 \mathrm{aB}$ & $3,00 \mathrm{bA}$ & $5,00 \mathrm{bB}$ \\
\hline CNA10900 & $1,00 \mathrm{aA}$ & $4,00 \mathrm{aB}$ & $2,50 \mathrm{bA}$ & $5,00 \mathrm{bB}$ \\
\hline CNA11014 & $1,00 \mathrm{aA}$ & $3,50 \mathrm{aB}$ & $2,50 \mathrm{bA}$ & $3,50 \mathrm{aA}$ \\
\hline Tio Taka & $2,00 \mathrm{aA}$ & $3,50 \mathrm{aB}$ & $2,50 \mathrm{bA}$ & $4,50 \mathrm{bB}$ \\
\hline SCS112 & $1,00 \mathrm{aA}$ & $4,00 \mathrm{aB}$ & $2,50 \mathrm{bA}$ & $5,00 \mathrm{bB}$ \\
\hline Andosan & $4,00 \mathrm{bA}$ & $4,00 \mathrm{aA}$ & $2,50 \mathrm{bA}$ & $4,50 \mathrm{bB}$ \\
\hline IRGA 424 & $1,00 \mathrm{aA}$ & $4,00 \mathrm{aB}$ & $2,00 \mathrm{bA}$ & $7,00 \mathrm{bB}$ \\
\hline BR IRGA 409 & $1,00 \mathrm{aA}$ & $4,50 \mathrm{aB}$ & $1,00 \mathrm{aA}$ & $6,00 \mathrm{bB}$ \\
\hline Jaçanã & $1,00 \mathrm{aA}$ & $3,50 \mathrm{aB}$ & $2,50 \mathrm{bA}$ & $6,00 \mathrm{bB}$ \\
\hline Metica1 & $1,00 \mathrm{aA}$ & $4,00 \mathrm{aB}$ & $3,50 \mathrm{cA}$ & $6,00 \mathrm{bB}$ \\
\hline Médias & $1,23 \mathrm{~A}$ & $4,01 \mathrm{~B}$ & $2,09 \mathrm{~A}$ & $4,55 \mathrm{~B}$ \\
\hline
\end{tabular}

*Médias seguidas pela mesma letra, minúscula na coluna e maiúscula na linha, não diferem estatisticamente pelo teste de Scott-Knott a 5\% de probabilidade.

doses utilizadas, na redução da severidade da mancha parda e mancha dos grãos, apesar de serem recomendados para o controle dessas doenças.

O genótipo $\mathrm{AB} 061050$ foi resistente à mancha parda e mancha de grãos. Celmer et al. (2007) constataram mais de $14 \%$ de tecido foliar com sintomas da mancha parda em plantas de arroz irrigado não pulverizadas com fungicidas. A mancha dos grãos atualmente é uma 
Tabela 3. Valores médios de severidade da mancha parda e mancha dos grãos em genótipos de arroz irrigado com (CF) ou sem (SF) aplicação de fungicidas na safra 2008/2009 em Formoso do Araguaia, Tocantins

\begin{tabular}{|c|c|c|c|c|}
\hline \multirow{3}{*}{ Genótipos } & \multicolumn{4}{|c|}{ Doenças } \\
\hline & \multicolumn{2}{|c|}{ Mancha parda } & \multicolumn{2}{|c|}{ Mancha dos grãos } \\
\hline & CF & SF & CF & SF \\
\hline AB061008 & $5,00 \mathrm{aA}$ & $5,00 \mathrm{aA}$ & $4,50 \mathrm{aA}$ & $4,50 \mathrm{aA}$ \\
\hline AB061021 & $3,50 \mathrm{bA}$ & $3,50 \mathrm{bA}$ & 3,50 aA & $3,50 \mathrm{aA}$ \\
\hline AB061050 & $3,00 \mathrm{bA}$ & $3,00 \mathrm{bA}$ & $2,50 \mathrm{aA}$ & $2,50 \mathrm{aA}$ \\
\hline AB061055 & $3,50 \mathrm{bA}$ & $3,50 \mathrm{bA}$ & $2,50 \mathrm{aA}$ & $2,50 \mathrm{aA}$ \\
\hline AB061179 & $5,00 \mathrm{aA}$ & $5,00 \mathrm{aA}$ & $3,50 \mathrm{aA}$ & $4,00 \mathrm{aA}$ \\
\hline AB061196 & $5,00 \mathrm{aA}$ & $5,00 \mathrm{aA}$ & $4,00 \mathrm{aA}$ & $4,00 \mathrm{aA}$ \\
\hline BRA051021 & $3,50 \mathrm{bA}$ & $3,50 \mathrm{bA}$ & $3,50 \mathrm{aA}$ & $3,50 \mathrm{aA}$ \\
\hline BRA051077 & $4,00 \mathrm{bA}$ & $4,00 \mathrm{bA}$ & $3,50 \mathrm{aA}$ & $3,50 \mathrm{aA}$ \\
\hline BRA051083 & $5,00 \mathrm{aA}$ & $5,00 \mathrm{aA}$ & $3,00 \mathrm{aA}$ & $3,00 \mathrm{aA}$ \\
\hline BRA051108 & 5,00 aA & 5,00 aA & 3,00 aA & 3,00 aA \\
\hline BRA051126 & $3,50 \mathrm{bA}$ & $3,50 \mathrm{bA}$ & 3,00 aA & $3,50 \mathrm{aA}$ \\
\hline BRA051129 & $3,00 \mathrm{bA}$ & $3,00 \mathrm{bA}$ & $3,00 \mathrm{aA}$ & $3,00 \mathrm{aA}$ \\
\hline BRA051130 & $3,00 \mathrm{bA}$ & $3,00 \mathrm{bA}$ & $2,50 \mathrm{aA}$ & $2,50 \mathrm{aA}$ \\
\hline BRA051134 & $3,50 \mathrm{bA}$ & $3,50 \mathrm{bA}$ & $3,50 \mathrm{aA}$ & $3,50 \mathrm{aA}$ \\
\hline BRA051135 & $3,50 \mathrm{bA}$ & $3,50 \mathrm{bA}$ & $3,00 \mathrm{aA}$ & $2,50 \mathrm{aA}$ \\
\hline BRA051250 & 5,00 aA & $5,00 \mathrm{aA}$ & 4,50 aA & $4,50 \mathrm{aA}$ \\
\hline CNA10892 & $5,00 \mathrm{aA}$ & 5,00 aA & 3,50 aA & 3,50 aA \\
\hline CNA10900 & 4,50 a $A$ & $4,50 \mathrm{aA}$ & $4,00 \mathrm{aA}$ & $4,00 \mathrm{aA}$ \\
\hline CNA11014 & $5,00 \mathrm{aA}$ & $5,00 \mathrm{aA}$ & 3,00 aA & $3,00 \mathrm{aA}$ \\
\hline Tio Taka & $4,00 \mathrm{bA}$ & $4,00 \mathrm{bA}$ & 3,50 aA & 3,50 aA \\
\hline SCS112 & $5,00 \mathrm{aA}$ & $5,00 \mathrm{aA}$ & $3,50 \mathrm{aA}$ & $4,00 \mathrm{aA}$ \\
\hline Andosan & 5,00 aA & $5,00 \mathrm{aA}$ & $4,00 \mathrm{aA}$ & $4,00 \mathrm{aA}$ \\
\hline IRGA 424 & $4,00 \mathrm{bA}$ & $4,00 \mathrm{bA}$ & $3,50 \mathrm{aA}$ & $3,50 \mathrm{aA}$ \\
\hline BRIRGA409 & $3,50 \mathrm{bA}$ & $3,50 \mathrm{bA}$ & 3,50 aA & 3,50 aA \\
\hline Jaçanã & $5,00 \mathrm{aA}$ & $5,00 \mathrm{aA}$ & $4,00 \mathrm{aA}$ & $4,50 \mathrm{aA}$ \\
\hline Metica1 & $4,00 \mathrm{bA}$ & $4,00 \mathrm{bA}$ & $3,00 \mathrm{aA}$ & $3,00 \mathrm{aA}$ \\
\hline Médias & $4,19 a$ & $4,19 \mathrm{a}$ & $3,46 \mathrm{a}$ & $3,40 \mathrm{a}$ \\
\hline
\end{tabular}

* Médias seguidas pela mesma letra, minúscula na coluna e maiúscula na linha, não diferem estatisticamente pelo teste de Scott-Knott a 5\% de probabilidade.

doença importante no arroz, principalmente quando a emissão das panículas coincide com chuvas intensas (Prabhu et al., 1995). A aplicação de fungicidas aumentou a massa média das sementes para a maioria dos genótipos testados, com um acréscimo médio de $0,52 \mathrm{~g}$ na massa de cem sementes (Tabela 4). Nas plantas das parcelas que receberam aplicação de fungicidas, a produtividade média dos genótipos foi de $1000 \mathrm{~kg}$ superior quando comparada com as plantas que náo receberam aplicação de fungicidas; foi observado, porém, aumento significativo em apenas cinco genótipos testados. O genótipo AB061055 com a maior produtividade dentre os demais genótipos, produziu acima de $9 \mathrm{~kg} \mathrm{ha}^{-1} \mathrm{com}$ ou sem a aplicação de fungicidas.

Observou-se que os genótipos BRA051077, BRA051129, BRA051250 e Jaçanã aumentaram até em $60 \%$ a produtividade com o controle das doenças fúngicas como pode ser verificado no genótipo BRA051077 que teve produtividade de $5600 \mathrm{~kg} \mathrm{ha}^{-1}$ na ausência da aplicação de fungicidas e de $9270 \mathrm{~kg} \mathrm{ha}^{-1} \mathrm{com}$ a aplicação de
Tabela 4. Valores médios da massa de cem sementes e produtividade dos genótipos de arroz irrigado com (CF) ou sem (SF) aplicação de fungicidas na safra 2008/2009, em Formoso do Araguaia, Tocantins

\begin{tabular}{|c|c|c|c|c|c|}
\hline \multirow{3}{*}{ Genótipos } & \multicolumn{5}{|c|}{ Variável de produção } \\
\hline & \multicolumn{2}{|c|}{$\begin{array}{l}\text { Massa de cem } \\
\text { sementes (g) }\end{array}$} & \multicolumn{3}{|c|}{$\begin{array}{l}\text { Produtividade } \\
\quad\left(\mathrm{kg} \mathrm{ha}^{-1}\right)\end{array}$} \\
\hline & CF & SF & CF & SF & $\%$ danos \\
\hline AB061008 & $2,67 \mathrm{aA}$ & $2,33 \mathrm{bA}$ & $7520 \mathrm{bA}$ & $6750 \mathrm{bA}$ & 10,2 \\
\hline AB061021 & $2,87 \mathrm{aA}$ & $2,06 \mathrm{bB}$ & $7300 \mathrm{bA}$ & $5670 \mathrm{bA}$ & 22,2 \\
\hline AB061050 & $2,79 \mathrm{aA}$ & $2,63 \mathrm{aA}$ & $6720 \mathrm{bA}$ & $6300 \mathrm{bA}$ & 6,3 \\
\hline AB061055 & $2,74 \mathrm{aA}$ & $2,44 \mathrm{aA}$ & $9170 \mathrm{aA}$ & $9100 \mathrm{aA}$ & 0,8 \\
\hline AB061179 & $2,68 \mathrm{aA}$ & $2,58 \mathrm{aA}$ & $6870 \mathrm{bA}$ & $6200 \mathrm{bA}$ & 9,8 \\
\hline AB061196 & $2,81 \mathrm{aA}$ & $2,09 \mathrm{bB}$ & $7420 \mathrm{bA}$ & $6350 \mathrm{bA}$ & 14,4 \\
\hline BRA051021 & $2,96 \mathrm{aA}$ & $2,83 \mathrm{aA}$ & $8600 \mathrm{aA}$ & $8170 \mathrm{aA}$ & 4,9 \\
\hline BRA051077 & 3,08 aA & $2,28 \mathrm{bB}$ & $9270 \mathrm{aA}$ & $5600 \mathrm{bB}$ & 39,6 \\
\hline BRA051083 & $3,29 \mathrm{aA}$ & $2,49 a B$ & $8450 \mathrm{aA}$ & $6600 \mathrm{bA}$ & 21,8 \\
\hline BRA051108 & $3,12 \mathrm{aA}$ & $2,42 \mathrm{aB}$ & $7800 \mathrm{bA}$ & $6450 \mathrm{bA}$ & 17,3 \\
\hline BRA051126 & $2,96 \mathrm{aA}$ & $2,37 \mathrm{aB}$ & $8350 \mathrm{aA}$ & $7920 \mathrm{aA}$ & 4,9 \\
\hline BRA051129 & $3,00 \mathrm{aA}$ & $2,08 \mathrm{bB}$ & $9050 \mathrm{aA}$ & $5650 \mathrm{bB}$ & 37,5 \\
\hline BRA051130 & $3,01 \mathrm{aA}$ & $2,37 \mathrm{aB}$ & $7950 \mathrm{bA}$ & $6900 \mathrm{bA}$ & 4,1 \\
\hline BRA051134 & $3,12 \mathrm{aA}$ & $2,14 \mathrm{bB}$ & $7770 \mathrm{bA}$ & $6370 \mathrm{aA}$ & 18,0 \\
\hline BRA051135 & $3,19 \mathrm{aA}$ & $2,25 \mathrm{bB}$ & $7350 \mathrm{bA}$ & $7300 \mathrm{aA}$ & 0,6 \\
\hline BRA051250 & $2,92 \mathrm{aA}$ & $2,52 \mathrm{aA}$ & $8820 \mathrm{aA}$ & $6120 \mathrm{bB}$ & 30,5 \\
\hline CNA10892 & $2,81 \mathrm{aA}$ & $2,46 a A$ & $7450 \mathrm{bA}$ & $7450 \mathrm{aA}$ & 0,0 \\
\hline CNA10900 & $2,92 \mathrm{aA}$ & $2,44 a B$ & $6900 \mathrm{bA}$ & $6770 \mathrm{bA}$ & 1,8 \\
\hline CNA11014 & 3,13 aA & $2,73 \mathrm{aA}$ & $6300 \mathrm{bA}$ & $6900 \mathrm{bA}$ & 0,0 \\
\hline Tio Taka & $2,71 \mathrm{aA}$ & $2,48 \mathrm{aA}$ & $8300 \mathrm{aA}$ & $8500 \mathrm{aA}$ & 0,0 \\
\hline SCS112 & $2,80 \mathrm{aA}$ & $2,61 \mathrm{aA}$ & $7420 \mathrm{bA}$ & $6100 \mathrm{bA}$ & 17,8 \\
\hline Andosan & $2,85 \mathrm{aA}$ & $2,54 \mathrm{aA}$ & $7450 \mathrm{bA}$ & $6000 \mathrm{bA}$ & 17,2 \\
\hline IRGA424 & $3,02 \mathrm{aA}$ & $2,50 \mathrm{aB}$ & $8770 \mathrm{aA}$ & $8170 \mathrm{aA}$ & 6,8 \\
\hline BRIRGA409 & 3,12 aA & $2,60 \mathrm{aB}$ & $7850 \mathrm{bA}$ & $6620 \mathrm{bA}$ & 15,6 \\
\hline Jaçanã & $3,04 \mathrm{aA}$ & $2,40 \mathrm{aB}$ & $8800 \mathrm{aA}$ & $6220 \mathrm{bB}$ & 29,1 \\
\hline Metica 1 & $2,95 \mathrm{aA}$ & $2,20 \mathrm{bB}$ & $9270 \mathrm{aA}$ & $7870 \mathrm{aA}$ & 15,0 \\
\hline Médias & $2,94 \mathrm{~A}$ & $2,42 \mathrm{~B}$ & $7900 \mathrm{~A}$ & 6900 B & \\
\hline
\end{tabular}

*Médias seguidas pela mesma letra, minúscula na coluna e maiúscula na linha, não diferem estatisticamente pelo teste de Scott-Knott a 5\% de probabilidade.

fungicidas (Tabela 4). O aumento na produtividade deste genótipo na presença de fungicidas pode ser atribuído provavelmente à redução na severidade da brusone nas folhas e nas panículas (Tabela 2), as quais afetam a produtividade do arroz (Bastianns et al., 1994; Frattini e Soave, 1974; Prabhu et al., 2006). Os genótipos BRA051077, BRA051129, BRA051250 e Jaçanã náo podem ser considerados tolerantes às doenças estudadas, pois só conseguiram aumentar a produtividade quando receberam a aplicação de fungicidas, sendo portanto, mais responsivos ao controle químico. Os genótipos suscetíveis às principais doenças exigem o uso intenso do controle químico e podem reduzir o lucro dos produtores. Dallagnoll et al. (2006) em avaliaçôes da severidade das doenças foliares na cultura do arroz, verificaram resultados semelhantes aos desta pesquisa, e verificaram que a aplicação de fungicidas reduziu a severidade das doenças foliares e a mancha dos grãos, possibilitando incrementos significativos na produtividade. Celmer et al. (2007), também em estudos sobre doenças foliares, verificaram influência positiva do 
controle químico das doenças foliares no rendimento de grãos de duas cultivares de arroz irrigado.

Com relação aos danos na produtividade, foram obtidos valores de $39,6 \%, 37,6 \%$ e $30,6 \%$ para os genótipos BRA051077, BRA051129 e BRA051250 respectivamente. Dessa forma, pode-se considerar que estes genótipos foram suscetíveis às doenças fúngicas, principalmente à brusone nas folhas e nas panículas e que a proteção com fungicidas foi eficaz resultando em aumento da produtividade. Segundo Prabhu (1995), o uso racional de fungicidas dentro de um controle integrado permite ganhos na produtividade do arroz que podem ultrapassar $27 \%$.

As maiores severidades (valores superiores a 6\%) das doenças foliares observadas no Estado do Tocantins são explicadas pelas condiçôes climáticas favoráveis, aliadas à alta densidade de semeadura e diversidade na população dos patógenos, devido tratar-se de áreas onde se cultiva arroz irrigado há mais de 30 anos. Estudos realizados por Anjos et al. (2009) e Dias Neto et al. (2010) demonstraram alta variabilidade na populaçáo de $P$. grisea na região do Vale do Araguaia, Tocantins, sendo detectadas 45 e 61 raças do fungo respectivamente. De acordo com os autores, a regiáo do Vale do Araguaia pode ser considerada o local de maior diversidade de $P$. grisea descrita até o momento no Brasil. Os maiores danos provocados pela brusone ocorrem principalmente em semeaduras com baixa diversidade genética de cultivares e em ambiente favorável (SANTos et al., 2005), o que é o caso da região do projeto Formoso localizado no Sul do Estado do Tocantins. Estes resultados demonstram que atualmente é difícil produzir arroz irrigado na regiāo do Vale do Araguaia sem o uso do controle químico; os genótipos estudados, provavelmente, são geneticamente semelhantes e não possuem variabilidade na resistência às doenças avaliadas, mesmo sob condiçóes ótimas para o progresso da brusone. Dessa forma, os programas de melhoramento desenvolvidos no Tocantins deverão buscar novas fontes de resistência a $P$. grisea e ou métodos de melhoramento que possibilitem a obtençáo de maior variabilidade genética das cultivares de arroz recomendados para a regiāo.

\section{CONCLUSÃO}

Em geral, os genótipos estudados proporcionam melhor rendimento com o uso do controle químico. O controle químico de doenças fúngicas em locais com condiçôes climáticas favoráveis é importante ferramenta a ser utilizada pelo orizicultor para estabilizar a produção de grãos. Os fungicidas utilizados no presente estudo não foram eficazes no controle de mancha parda e da mancha dos grãos.

\section{REFERÊNCIAS}

ANJOS, L.M.; SANTOS, G.R.; DIAS NETO, J.J.; OLIVEIRA, W.F.; CASTRO NETO, M.D. Identificação de raças fisiológicas de Magnaporthe grisea em áreas de arroz irrigado no Estado do Tocantins. Tropical Plant Pathology, v.34, p.167-170, 2009.

BALARDIN, R.S.; BORIN, R.C. Doenças na cultura do arroz irrigado. Santa Maria: UFSM, 2001. 48p.

BASTIAANS, L.; RABBINGE, R.; ZADOKS, J.C. Understanding and modeling leaf blast effects on crop physiology and yield. In: ZEIGLER, R.S.; LEONG, S.A; TENG, P.S. (Ed.). Rice blast disease. Wallingford: CAB, 1994. p.357-380.

BONMAN, J.M.; KHUSH, G.S.; AND NELSON, R.J. Breeding rice for resistance to pests. Annual Review of Phytopathology, v.20, p.507-528, 1992.

BRITO, ANDRÉ H.; VON PINHO, R.G.; POZZA, E.A.; PEREIRA, J.R.A.L.; FARIA FILHO, E.N. Efeito da cercosporiose no rendimento de híbridos comerciais de milho. Fitopatologia Brasileira, v.32, p.472-479, 2007.

CELMER, A.; MADALOSSO, M.G.; DEBORTOLI, M.P.; NAVARINI, L.; BALARDIN, R.S. Controle químico de doenças foliares na cultura do arroz irrigado. Pesquisa Agropecuária Brasileira, v.42, p.901-904, 2007.

COSTA, J.L.S. Alternaria padwickii e Curvularia lunata: patogenicidade e transmissão por sementes de arroz irrigado. Fitopatologia Brasileira, v.16, p.15-18, 1991.

DALLAGNOL, J.L.; NAVARINI, L.; BALARDIN, R.S.; GOSENHEIMER, A.; MAFFINI, A.A. Dano das doenças foliares na cultura do arroz irrigado e eficiência de controle dos fungicidas. Revista Brasileira de Agrociência, v.12, p.313-318, 2006.

DIAS NETO, J.J.; SANTOS, G.R.; ANJOS, L.M.; RANGEL, P.H.N.; FERREIRA, M.E. Hot spots for diversity of Magnaporthe oryzae physiological races in irrigated rice fields in Brazil. Pesquisa Agropecuária Brasileira, v.45, p.252-260, 2010.

EMPRESA BRASILEIRA DE PESQUISA AGROPECUÁRIA EMBRAPA. Manual de métodos de análises de solo. 2.ed. Rio de Janeiro: Ministério da Agricultura e do Abastecimento, 1997. 212p.

FRATTINI, J.A.; SOAVE, J. Tentativa de avaliação de perdas causadas pela brusone na cultura de arroz no Estado de São Paulo. Revista de Agricultura, v.49, p.101-108, 1974.

INTERNATIONAL RICE RESEARCH INSTITUTE - IRRI. Standard Evaluation Systen for Rice. Manila, 1996. 52p.

OLIVEIRA, W.F.; PIMENTEL, D.M.; ALBERNAZ, R.S.; MACHADO, L.A.; BATISTA, R.G.; RAMALHO, V. Efeito de produtos fitossanitários no tratamento de sementes de arroz (Oryza sativa L.) visando ao controle de Pyricularia grisea. Pesquisa Agropecuária Tropical, v.31, p.43-46, 2001.

PRABHU, A.S. Situação atual do arroz de sequeiro e estratégias de controle. Fitopatologia Brasileira, v.20, p.277, 1995. 
PRABHU, A.S.; FILIPPI, M.C. Arroz (Oryza sativa L.) Controle de doenças. In: VALE, F.X.R.; ZAMBOLIN, L. Controle de doenças de plantas: grandes culturas. Viçosa: Universidade Federal de Viçosa, 1997. v.1, p.51-79.

PRABHU, A.S.; FILIPPI, M.C.; FARIA, J.C.; ARAÚJO, L.G. Caracterização Fenotípica e Genética da Virulência de Pyricularia grisea em Cultivares de Arroz Irrigado no Estado do Tocantins. Santo Antônio de Goiás: EMBRAPA/CNPAF, 2004. 32p.

PHABHU, A.S.; FILLIPI, M.C.C.; RIBEIRO, A.S. Doenças e seu controle. In: SANTOS, A.B.; STONE, L.F.; VIEIRA, N.R.A. (Ed.). A cultura do arroz no Brasil. 2.ed. Santo Antônio de Goiás: EMBRAPA/CNPAF, 2006. p.561-590.

PRABHU, A.S.; BEDENDO, I.P.; FILIPPI, M.C. Principais doenças do arroz no Brasil. 3.ed. Goiânia: EMBRAPA/CNPAF, 1995. 43p. ( Documentos, 2)

SANTOS, G.R.; COSTA, W.M.; COSTA, H. Incidência de mancha parda do arroz no Projeto Formoso, Estado do Tocantins. Fitopatologia Brasileira, v.19, p.299, 1994.

SANTOS, G.R.; SABOYA, L.M.F.; RANGEL, P.H.N.; OLIVEIRA-FILHO, J.C. Resistência de genótipos de arroz a doenças no sul do Estado do Tocantins. Bioscience Journal, v.18, p.3-12, 2002.

SANTOS, G.R.; RANGEL, P.H.N.; SANTIAGO, C.M.; LEÁO, F.F.; MARRA, B.; ALMEIDA JUNIOR, D. Reação a doenças e caracteres agronômicos de genótipos de arroz de várzeas no estado do Tocantins. Revista Agropecuária Técnica, v.26, p.4145, 2005.

SECRETARIA DA AGRICULTURA, PECUARIA E ABASTECIMENTO DO ESTADO DO TOCANTINSSEAGRO. Levantamento sistemático da produção agrícola-Palmas, Tocantins, 2009.

SILVA, I.P.; SILVA, J.A.A. Métodos estatísticos aplicados à pesquisa científica: uma abordagem para profissionais da pesquisa agropecuária. Recife: UFRPE, 1999. 305p.

SILVA, G.B.; PRABHU, A.S.; ZIMMERMANN, F.J.P. Manejo integrado da brusone em arroz no plantio direto e convencional. Pesquisa Agropecuária Brasileira, v.38, p.481-487, 2003.

SOUZA, N.S.; BARROS, L.G.; PRABHU, A.S; Incidência de mancha de grãos do arroz em relação à época de plantio e aplicação de fungicidas. Cuiabá: EMPAER, MT, 1993. 19p. 